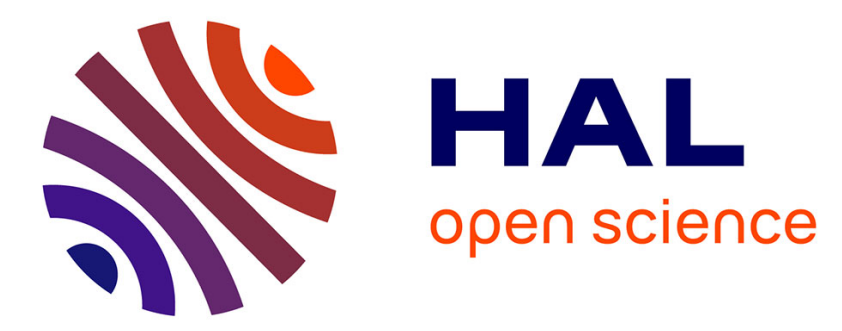

\title{
Nonlinear optical characterization of tetraphenylporphyrin in the picosecond regime
}

C. Cassagne, M. Chniti, Cid de Araújo, H. Belmabrouk, Georges Boudebs

\section{To cite this version:}

C. Cassagne, M. Chniti, Cid de Araújo, H. Belmabrouk, Georges Boudebs. Nonlinear optical characterization of tetraphenylporphyrin in the picosecond regime. 17th International Conference on Transparent Optical Networks (ICTON2015), Jul 2015, Budapest, Hungary. 10.1109/ICTON.2015.7193435 . hal-02442883

\section{HAL Id: hal-02442883 \\ https://hal.science/hal-02442883}

Submitted on 16 Apr 2021

HAL is a multi-disciplinary open access archive for the deposit and dissemination of scientific research documents, whether they are published or not. The documents may come from teaching and research institutions in France or abroad, or from public or private research centers.
L'archive ouverte pluridisciplinaire HAL, est destinée au dépôt et à la diffusion de documents scientifiques de niveau recherche, publiés ou non, émanant des établissements d'enseignement et de recherche français ou étrangers, des laboratoires publics ou privés. 


\title{
Nonlinear Optical Characterization of Tetraphenylporphyrin in the Picosecond Regime
}

\author{
C. Cassagne ${ }^{(1)}$, M. Chniti ${ }^{(1,2)}$, Cid B. de Araújo $^{(3)}$, H. Belmabrouk ${ }^{(2)}$, and G. Boudebs ${ }^{(1, *)}$ \\ (1) LUNAM Université, Université d'Angers, LPhiA, EA 4464, 2 Boulevard Lavoisier, 49045 Angers France \\ (2) Laboratory Electronic and Microelectronic, University of Monastir, Tunisia \\ (3) Departamento de Física, Universidade Federal de Pernambuco, 50670-901 Recife, PE, Brazil \\ (*) Tel:(33) 2.41.73.54.26,Fax:(33) 2.41.73.52.16, email: georges.boudebs@univ-angers.fr
}

\begin{abstract}

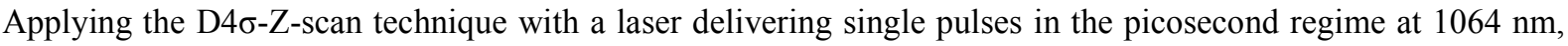
$532 \mathrm{~nm}$, and $355 \mathrm{~nm}$ we report on the nonlinear (NL) optical properties of 5,10,15,20-Tetraphenyl-21H,23Hporphine (TPP) and 5,10,15,20-Tetraphenyl-21H,23H-porphine zinc (ZnTPP) solutions prepared in chlorobenzene. Accurate measurements of the NL coefficients for 4 concentrations in both compounds are provided. The results show no response in the IR for both materials, negative NL refraction for TPP in the green changing sign to positive for ZnTPP and positive NL refraction in the UV for both compositions. The NL absorption of these materials is quite huge in the visible range where applications for optical limiting are needed. Keywords: porphyrin, nonlinear absorption, nonlinear refractive index, D4 $\sigma-Z$-scan technique.
\end{abstract}

\section{INTRODUCTION}

Large Porphyrins (Pphs) are biological macromolecules that play a crucial role in various processes in nature such photosynthesis and oxygen transport in cells, as well as applications such as in solar photovoltaic devices [1] and photodynamic cancer therapy [2]. Synthesis and experimental investigation of nonlinear (NL) optical properties of Pphs have been reported by several groups [3, 4]. The large interest in the NL properties of Pphs is due to their unique electronic, optical and biochemical properties $[5,6]$ as well as the high stability and architectural flexibility that provide a very good basis to finely tune their optical response.

In the present article, we report on experiments with TPP and ZnTPP using an Nd: YAG laser operating in the picosecond regime at $10 \mathrm{~Hz}$ repetition rate to measure the nonlinear absorption (NLA) coefficients and NL refractive indices of the Pphs based solutions at three different wavelengths (1064 nm, $532 \mathrm{~nm}$ and $355 \mathrm{~nm}$ ) and four different concentrations. The experiments were performed calculating the beam waist relative variation (BWRV) using D4 $\sigma$ intensity profile measurements combined to Z-scan method [7]. It is referred here as D4 $\sigma$ Zscan technique [8]. It was possible to determine the sign and the magnitude of the NL refractive indices even in the presence of high NLA at relatively high concentration which is the case when dealing with Pphs. Simple linear relations were empirically obtained allowing a correlation between the NL parameters and the linear absorption coefficient.

\section{EXPERIMENTAL}

\subsection{UV-VIS Absorption}
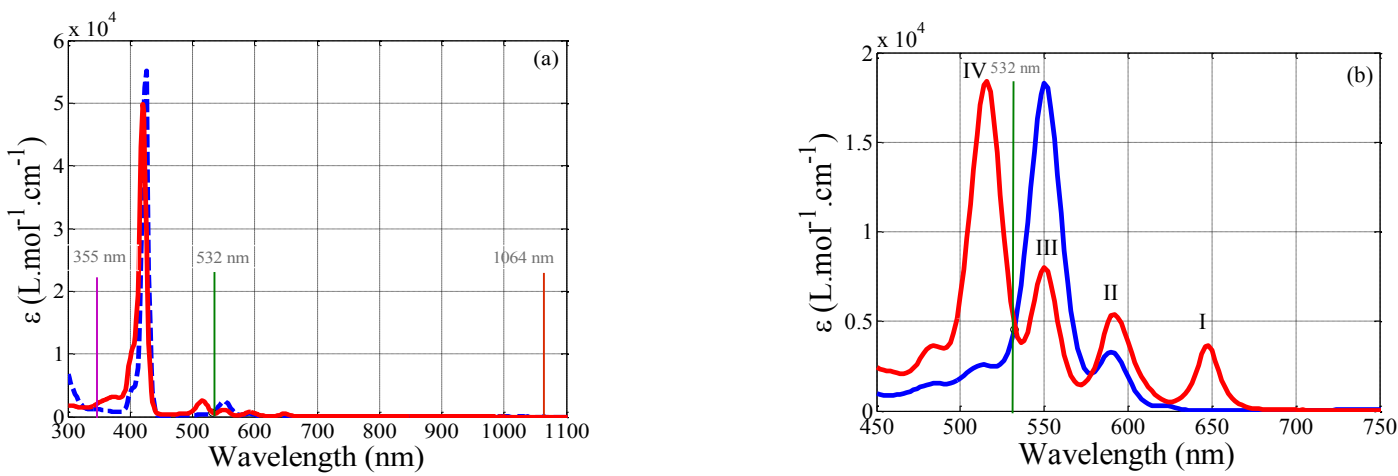

Figure 1: Molar extinction coefficients $\varepsilon$ versus wavelengths. Solid (red) line for TPP; dashed (blue) line for ZnTPP. Porphyrin concentrations for both compounds: (a) $10^{-4} \mathrm{~mol} / \mathrm{L}$; (b) $10^{-3} \mathrm{~mol} / \mathrm{L}$. The vertical straight lines indicate the laser wavelengths at $1064 \mathrm{~nm}, 532 \mathrm{~nm}$ and $355 \mathrm{~nm} . \mathrm{I}, I I, I I I, I V$ are the TPP Q-bands.

The electronic absorption spectra were recorded in chlorobenzene solution. Figure 1(a) shows the optical absorption spectrum of TPP in solid (red) line and ZnTPP dashed (blue) line measured from $300 \mathrm{~nm}$ to $1100 \mathrm{~nm}$, at room temperature. The strong absorption band centered at $\approx 420 \mathrm{~nm}(\approx 2.96 \mathrm{eV})$ is called Soret band (also 
called B band). Figure 1(b) shows the spectra of the samples measured at concentration of $10^{-3} \mathrm{M}$. The bands in the region from $\approx 500$ to $\approx 700 \mathrm{~nm}$ region are the $\mathrm{Q}$ bands that are attributed to transitions associated to the $\pi-\pi^{*}$ conjugate system. Also drawn in Fig. 1(a) are vertical lines that indicate the laser wavelengths used in the experiments. In Table 1 we indicated the wavelength corresponding to the maximum of absorption, $\lambda_{\max }$, and the corresponding molar extinction coefficient for each band.

\subsection{Nonlinear Measurements}

The experimental setup used to implement the D4 $\sigma-Z$-scan technique is described in details in [8]. For the characterization of the nonlinear refraction and absorption, the solution were inside a $1 \mathrm{~mm}$ thick quartz cell. The NL measurements were made at $355 \mathrm{~nm}, 532 \mathrm{~nm}$ and $1064 \mathrm{~nm}$. The results are shown in Tables 1 and 2. At $1064 \mathrm{~nm}$ the TPP and ZnTPP solutions did not show any NL response even for high concentrations. Experiments were made at $15 \mathrm{GW} / \mathrm{cm}^{2}$ in solutions with concentration of $10^{-3} \mathrm{M}$ and for pure chlorobenzene. The measured NL refraction was approximately equal for the Pph solutions and for pure chlorobenzene. It was found $n_{2}=(0.16 \pm 0.05) \times 10^{-18} \mathrm{~m}^{2} / \mathrm{W}$ and $\beta<0.02 \mathrm{~cm} / \mathrm{GW}$ which is smaller than the sensitivity of the apparatus. At $532 \mathrm{~nm}$ and $I_{0}=8.5 \mathrm{GW} / \mathrm{cm}^{2}$, chlorobenzene shows a NL refractive index equal to $n_{2}=(0.35 \pm 0.05) \times 10^{-18} \mathrm{~m}^{2} / \mathrm{W}$ and $\beta<0.02 \mathrm{~cm} / \mathrm{GW}$. The NL refraction behavior of TPP and ZnTPP is illustrated in Figs. 2(a) and 2(b), respectively; the data presented were obtained at $2.1 \mathrm{GW} / \mathrm{cm}^{2}$. The BWRV profile with the peak after the valley indicates that the TPP presents a negative NL refractive index exhibiting self-defocusing at this wavelength. The open-aperture Z-scan data, presented as insets of both figures, illustrate the NLA behavior. These results illustrate clearly the influence of Zn on the NL response at $532 \mathrm{~nm}$ : (i) the sign of $\mathrm{n}_{2}$ is positive for ZnTPP while it is negative for TPP; (ii) the 2PA coefficient of ZnTPP is larger than in TPP. Note that in Table 1 the positive value of $n_{2}$ for TPP is due to the low concentration $\left(0.12 \times 10^{-3} \mathrm{M}\right)$ showing the result of the competition between the positive NL refraction due to chlorobenzene alone and the small amount of TPP molecules dissolved inside.
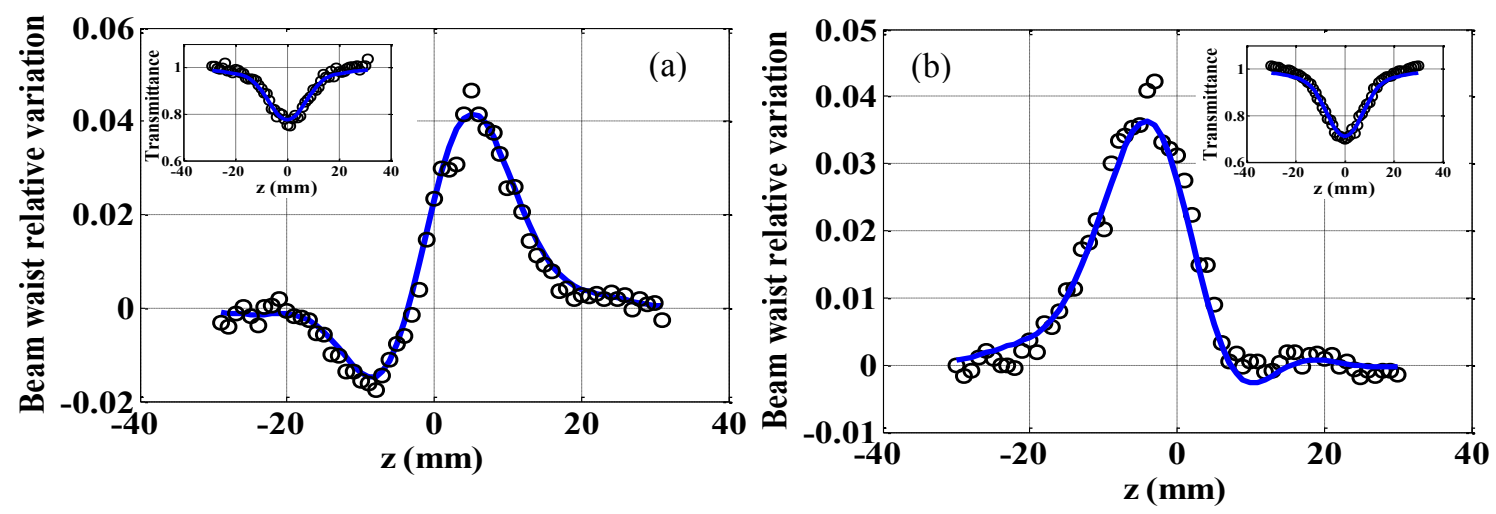

Figure 2: Beam waist relative variation versus $z$, the sample position at $532 \mathrm{~nm}$. Sample thickness: $1 \mathrm{~mm}$. Pph solution concentration: $10^{-3}$ M. Laser intensity: $I_{0}=2.1 \mathrm{GW} / \mathrm{cm}^{2}$. (a) Sample: TPP $\left(\alpha=1126 \mathrm{~m}^{-1}\right)$; (b) sample: $\operatorname{ZnTPP}\left(\alpha=1048 \mathrm{~m}^{-1}\right)$. The insets represent the open aperture Z-scan traces and the blue lines represent the best fit of the data.

At $355 \mathrm{~nm}$ the experiments with pure chlorobenzene gives $n_{2}=(0.55 \pm 0.1) \times 10^{-18} \mathrm{~m}^{2} / \mathrm{W}$ and $\beta=(0.35 \pm 0.06) \mathrm{cm} / \mathrm{GW}$. Due to the high linear absorption coefficient $\left(\alpha=4221 \mathrm{~m}^{-1}\right)$ of Pph solution at concentration $10^{-3} \mathrm{M}$, the NL measurement at low intensity was not possible because even in the linear regime, in order to detect a signal at the CCD, the needed laser intensity was high enough to induce unwanted NLA leading to non-reliable coefficient values. The measurement was possible starting from concentration of $0.5 \times 10^{-3}$ with $I_{0}=4 \mathrm{GW} / \mathrm{cm}^{2}$. TPP and ZnTPP solutions presented positive $n_{2}$ (self-focusing) and strong NLA. The measured NL parameters for solutions with different concentrations of TPP and ZnTPP are shown in Table1 for $\lambda=532 \mathrm{~nm}$ and in Table 2 for $\lambda=355 \mathrm{~nm}$. The $2 \mathrm{PA}$ cross section, $\sigma_{2}$, was calculated from $\beta$, the NL absorption coefficient, using the relation $\sigma_{2}\left(\mathrm{~cm}^{4} \cdot \mathrm{s} \cdot\right.$ photon $\left.^{-1}\right)=10^{3} \mathrm{~h} v \beta / N C$, where $N_{\mathrm{A}}$ is the Avogadro number, $C$ is the Pph concentration, $h$ the Planck's constant and $v$ is the frequency of the incident light. The $\sigma_{2}$ values are indicated in Tables 1-2 in GM units $\left(1 \mathrm{GM}=10^{-50} \mathrm{~cm}^{4} \cdot \mathrm{s} \cdot\right.$ photon $\left.^{-1}\right)$. Note that the values of $\sigma_{2}$ are not dependent on the Pph concentration, as expected. 
Table 1. Linear and nonlinear parameters of TPP and ZnTPP (with different concentrations), at $532 \mathrm{~nm} . \alpha_{532}$ is the linear absorption coefficient, $n_{2}$ is the effective $N L$ refractive index, $\beta$ is the NLA coefficient, $I_{0}$ is the laser peak intensity and $\sigma_{2}$ is the 2PA cross-section in GM units.

\begin{tabular}{|l|c|c|c|c|c|c|}
\hline & $\begin{array}{c}\text { Concentration } \\
\left(\times 10^{-3} \mathrm{M}\right)\end{array}$ & $\begin{array}{c}\alpha_{532} \\
\left(\mathrm{~cm}^{-1}\right)\end{array}$ & $\begin{array}{c}I_{0} \\
\left(\mathrm{GW} / \mathrm{cm}^{2}\right)\end{array}$ & $\begin{array}{c}n_{2} \times 10^{-18} \\
\left(\mathrm{~m}^{2} / \mathrm{W}\right)\end{array}$ & $\begin{array}{c}\beta \\
(\mathrm{cm} / \mathrm{GW})\end{array}$ & $\begin{array}{c}\sigma_{2} \\
(\mathrm{GM})\end{array}$ \\
\hline Chlorobenzene & & & $2.0-8.0$ & $0.35 \pm 0.05$ & $<0.06$ & \\
\hline & 1 & 11.2 & & $-2.7 \pm 0.5$ & $5.5 \pm 0.8$ & $3.4 \times 10^{5}$ \\
TPP & 0.48 & 5.45 & 2.1 & $-0.9 \pm 0.3$ & $2.8 \pm 0.4$ & $3.6 \times 10^{5}$ \\
& 0.24 & 2.7 & & $-0.26 \pm 0.4$ & $1.3 \pm 0.3$ & $3.4 \times 10^{5}$ \\
& 0.12 & 1.4 & & $0.19 \pm 0.1$ & $0.7 \pm 0.2$ & $3.6 \times 10^{5}$ \\
\hline & 0.94 & 10.4 & & $1.7 \pm 0.3$ & $7.8 \pm 0.1$ & $5.1 \times 10^{5}$ \\
ZnTPP & 0.47 & 5.3 & 2.1 & $0.9 \pm 0.2$ & $4.0 \pm 0.5$ & $5.3 \times 10^{5}$ \\
& 0.23 & 2.7 & & $0.6 \pm 0.1$ & $2.0 \pm 0.3$ & $5.4 \times 10^{5}$ \\
& 0.11 & 1.1 & & $0.5 \pm 0.1$ & $1.0 \pm 0.1$ & $5.6 \times 10^{5}$ \\
\hline
\end{tabular}

Table 2. Linear and nonlinear parameters of TPP and ZnTPP (with different concentrations), at $355 \mathrm{~nm} . \alpha_{355}$ is the linear absorption coefficient, $n_{2}$ is the effective $N L$ refractive index, $\beta$ is the NLA coefficient, $I_{0}$ is the laser peak intensity and $\sigma_{2}$ is the $2 P A$ cross-section in GM units.

\begin{tabular}{|l|c|c|c|c|c|c|}
\hline & $\begin{array}{c}\text { Concentration } \\
\left(\times 10^{-3} \mathrm{M}\right)\end{array}$ & $\begin{array}{c}\alpha_{355} \\
\left(\mathrm{~cm}^{-1}\right)\end{array}$ & $\begin{array}{c}I_{0} \\
\left(\mathrm{GW} / \mathrm{cm}^{2}\right)\end{array}$ & $\begin{array}{c}n_{2} \times 10^{-18} \\
\left(\mathrm{~m}^{2} / \mathrm{W}\right)\end{array}$ & $\begin{array}{c}\beta \\
(\mathrm{cm} / \mathrm{GW})\end{array}$ & $\begin{array}{c}\sigma_{2} \\
(\mathrm{GM})\end{array}$ \\
\hline Chlorobenzene & & & $7.6-25$ & $0.5 \pm 0.1$ & $0.35 \pm 0.06$ & - \\
\hline & 1 & 42.2 & & - & - & - \\
TPP & 0.48 & 20.4 & 4.0 & $2.8 \pm 0.6$ & $6.4 \pm 0.8$ & $1.2 \times 10^{6}$ \\
& 0.24 & 10.2 & & $1.4 \pm 0.2$ & $3.5 \pm 0.3$ & $1.3 \times 10^{6}$ \\
& 0.12 & 5.2 & & $0.8 \pm 0.1$ & $1.7 \pm 0.2$ & $1.3 \times 10^{6}$ \\
\hline & 0.94 & 18.9 & & $1.0 \pm 0.2$ & $7.3 \pm 1$ & $0.7 \times 10^{6}$ \\
ZnTPP & 0.47 & 9.4 & 4.0 & $0.6 \pm 0.1$ & $3.4 \pm 0.5$ & $0.7 \times 10^{6}$ \\
& 0.23 & 4.6 & & $0.5 \pm 0.1$ & $1.8 \pm 0.3$ & $0.7 \times 10^{6}$ \\
& 0.11 & 2.2 & & $0.4 \pm 0.1$ & $1.2 \pm 0.2$ & $1.0 \times 10^{6}$ \\
\hline
\end{tabular}

In Fig. 3, we summarized the values of the NL coefficients of TPP and ZnTPP at $532 \mathrm{~nm}$ and $355 \mathrm{~nm}$ as a function of the linear absorption coefficient, $\alpha$ (which is proportional to the Pph concentration). Figure 3(a) shows the variation of $n_{2}$ versus $\alpha$ for ZnTPP (data in blue color): empty squares at $355 \mathrm{~nm}$, filled squares at $532 \mathrm{~nm}$ and for TPP (red data) empty circles at $355 \mathrm{~nm}$, filled circles at $532 \mathrm{~nm}$. At very low concentration (very low $\alpha$ ), the intersection of the straight lines with the vertical axis occurs for a positive value of $\mathrm{n}_{2}$ corresponding to pure chlorobenzene (within the experimental error). Figure 3(b) shows the variation of $\beta$ versus $\alpha$ for ZnTPP (blue data): empty squares at $355 \mathrm{~nm}$, filled squares at $532 \mathrm{~nm}$ and for TPP (red data) empty circles at $355 \mathrm{~nm}$, filled circles at $532 \mathrm{~nm}$. At very low concentration, the intersection of the straight lines with the vertical axis occurs at the value of $\beta$ corresponding to pure chlorobenzene. Notice that the maximum efficiency for optical limiting is obtained at $532 \mathrm{~nm}$. Indeed, for a given $\alpha$ the NLA is higher at $532 \mathrm{~nm}$ for both Pphs compositions when compared to the contribution obtained at $355 \mathrm{~nm}$ as noticed by the effective slope of the linear fits.
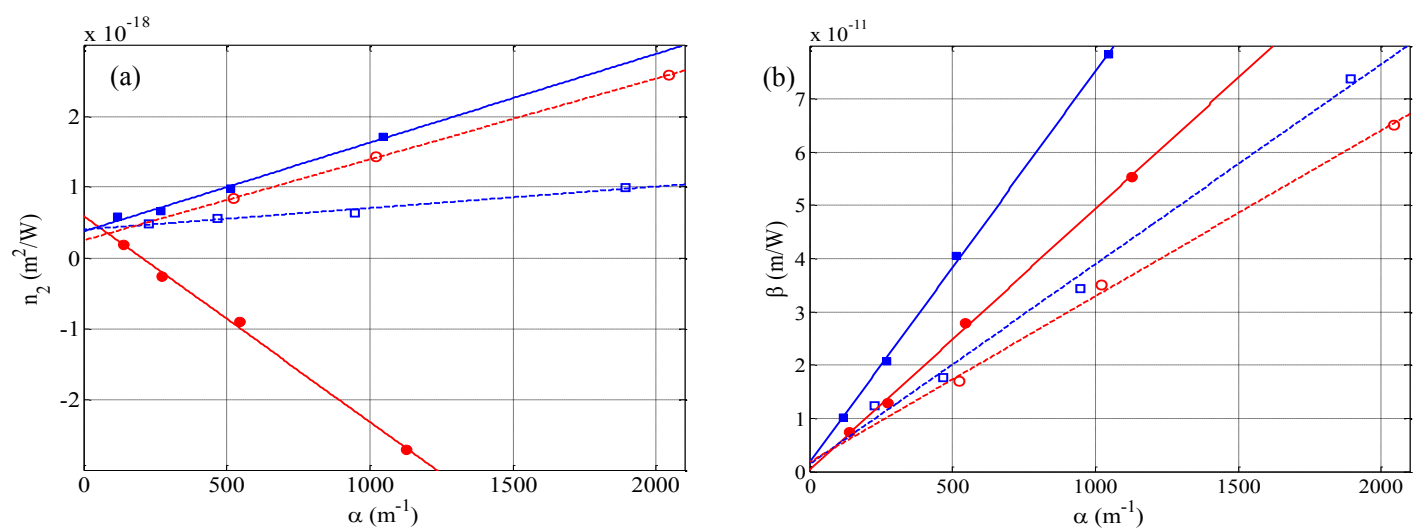

Figure 3: (a) Values of $n_{2}$ versus the linear absorption coefficient for ZnTPP: (blue data) empty squares in the $U V(355 \mathrm{~nm})$, filled squares in the green $(532 \mathrm{~nm})$ and for TPP (red data) empty circles in the UV $(355 \mathrm{~nm})$, filled circles in the green $(532 \mathrm{~nm})$. (b) Values of $\beta$ versus the linear absorption coefficient for ZnTPP: (blue data) empty squares in the UV, filled squares in the green and for TPP (red data) empty circles in the UV, filled circles in the green. The dashed and solid lines are the linear fits.

\subsection{Discussion}

To investigate the contribution of the solvent, D4 $\sigma$-Z-scan experiments were performed with pure chlorobenzene. As expected, no significant NL absorption was detected at $1064 \mathrm{~nm}$ and $532 \mathrm{~nm}$; at $355 \mathrm{~nm}$. The measured $\mathrm{n}_{2}$ values show a normal dispersion behavior with respect to wavelengths. This decreasing behavior 
with $\lambda$ suggests the high reliability of the $n_{2}$ absolute values determined via the BWRV measurements [8] for transparent liquids far away from any absorption band. At $1064 \mathrm{~nm}$ both Pphs solutions did not show NLA because they are transparent at this wavelength. Although the energy of two laser photons falls into the Q bands region (see Fig. 1b) these bands are relatively weak. For excitation at $532 \mathrm{~nm}$ the energy of two photons corresponds to the energy of one photon at $266 \mathrm{~nm}$ that implies a large NLA.

Based on the results of [9] studying the same molecules and as in [10] we concluded that the effective thirdorder susceptibility governing the NL response of TPP and ZnTPP is due to a cascade process $\chi^{(1)}: \chi^{(1)}$ (acting as an effective third-order susceptibility). In this process the first $\chi^{(1)}$ is mainly related to the ground state absorption and the second $\chi^{(1)}$ is mainly influenced by the excited state refraction. The first excitation step is due to the bound electrons in the Pph molecules in the singlet $\mathrm{S}_{0}$. The second step is dependent on the number of molecules in the excited singlet $S_{1}$ and is related to the change in the refractive index per unit photoexcited molecule. The population of the $S_{1}$ states will always be small due to their fast relaxation time [9].

Finally, the herein reported NLA coefficients when compared to other values found for organic compounds [11] are much larger. Furthermore the effective 2PA cross section values measured in the commercial Pphs are of the same order of magnitude than those reported for porphyrin supramolecules [12].

\section{CONCLUSIONS}

In summary, the third-order nonlinearity of TPP and ZnTPP was investigated applying the D4 $\sigma$-Z-scan technique in the ps regime at $355 \mathrm{~nm}, 532 \mathrm{~nm}$ and $1064 \mathrm{~nm}$. Beside a change of the NL refractive index from negative to positive due to the presence of $\mathrm{Zn}$ it was measured large NLA coefficients for both compounds. The NL behaviour observed indicates the large potential of TPP and ZnTPP for optical limiting applications because of their large 2PA cross-section of several thousand GM units. The NL response is attributed to an effective $\chi_{\text {eff }}^{(3)}$ dominated by a cascade process. The reported results indicate that ground state absorption and excited state refraction dominate in these experiments and therefore linear and effective 2PA strengths are linked.

\section{REFERENCES}

[1] H. Imahori and S. Fukuzumi: Porphyrin and fullerene-based molecular photovoltaic device, Adv. Funct. Mater. 2004, 14, 525.

[2] B. Minaev and M. Lindgren: Vibration and fluorescence spectra of porphyrin-cored 2,2-bis(methylol)propionic acid dendrimers, Sensors, 2009, 9, 1937.

[3] M.O. Senge, M. Fazekas, E.G.A. Notaras, W.J. Blau, M. Zawadzka, O.B. Locos, and E.M.N. Mhuircheartaigh: Nonlinear optical properties of porphyrins, Adv. Mater. 2007, 19, 2737.

[4] C.G. Liu, D.F. Zhang, M.L. Gao, and X.H. Sun: Computational study on second-order nonlinear optical properties of a series of axially substituted zinc porphyrin, Comp. Theor. Chem. 2013, 1027, 26.

[5] Z. Valicsek and O. Horváth: Application of the electronic spectra of porphyrins for analytical purposes: The effects of metal ions and structural distortions, Microchem. J. 2013,107, 47.

[6] N.M. Barbosa Neto, D.S. Correa, L. De Boni, G.G. Parra, L. Misoguti, C.R. Mendonça, I.E. Borissevitch, S.C. Zílio, and P.J. Gonçalves: Excited states absorption spectra of porphyrins-solvent effects, Chem. Phys. Lett. 2013, 587, 118.

[7] M. Sheik-Bahae, A.A. Said, T.H. Wei, D. Hagan, and E.W. Van Stryland: Sensitive measurement of optical nonlinearities using a single Beam, IEEE J. Quantum Electron. 1990, 26, 4.

[8] G. Boudebs, V. Besse, C. Cassagne, H. Leblond, C.B. De Araújo: Nonlinear characterization of materials

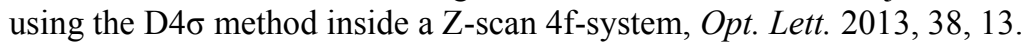

[9] W. Blau, H. Byrne, and W.M. Dennis: Reverse saturable absorption in tetraphenyl porphyrins, Opt. Commun. 1998, 56, 25-29.

[10] T.H. Wei, D.J. Hagan, M.J. Sence, E.W. Van Stryland, J.W. Perry, D.R. Coulter: Direct measurements of nonlinear absorption and refraction in solutions of phthalocyanines, Appl. Phys. B. 1992, 54, 46.

[11] L. De Boni, A.A. Andrade, S.B. Yamaki, L. Misoguti, S.C. Zilio, D.Z. Atvars Teresa, and C.R. Mendonca: Two-photon absorption spectrum in diazoaromatic compounds, Chem. Phys. Lett. 2008, 463, 360.

[12] K. Ogawa and Y. Kobuke: Nonlinear absorption by porphyrin supramolecules, in Nonlinear Optics, N. Kamanina (Ed.), ISBN: 978-953-51-0131-4, InTech, Available from: http://www.intechopen.com/books/nonlinear-optics/nonlinear-absorption-by-porphyrin-supramolecules. 